\title{
Epilepsy in inborn errors of metabolism: two cases with unusual presentation
}

\author{
Suvasini Sharma ${ }^{a, *}$, Puneet Jain ${ }^{a, d}$, Chellamuthu Prabaharan ${ }^{a}$, \\ Jeedan Hemrom ${ }^{a}$, Seema Kapoor ${ }^{b}$, Chandrawati Kumari ${ }^{b}$, Atin Kumar ${ }^{c}$, \\ Harish Pemde ${ }^{a}$, Satinder Aneja ${ }^{a}$ \\ ${ }^{a}$ Department of Pediatrics, Lady Hardinge Medical College and Associated Kalawati Saran Children's Hospital, \\ New Delhi 110001, India \\ ${ }^{\mathrm{b}}$ Department of Pediatrics, Maulana Azad Medical College and Associated Lok Nayak Hospital, New Delhi 110002, \\ India \\ ${ }^{\mathrm{c}}$ Department of Radiodiagnosis, All India Institute of Medical Sciences, New Delhi 110016, India \\ ${ }^{\mathrm{d}}$ Division of Pediatric Neurology, Department of Pediatrics, BLK Super Speciality Hospital, Pusa Road, New Delhi \\ 110005, India
}

\section{A R T I C L E I N F O}

Article history:

Received 10 September 2013

Accepted 21 March 2014

Available online 10 June 2014

Keywords:

Glutaric aciduria

Maple syrup urine disease

Epileptic encephalopathy

West syndrome

\begin{abstract}
A B S T R A C T
Inherited metabolic disorders are a rare cause of epilepsy in children. We describe a case of Glutaric aciduria type 1 presenting with West syndrome and a case of intermittent Maple syrup urine disease presenting with epileptic encephalopathy. Early diagnosis and institution of appropriate therapy may be life saving and may improve the long term neurodevelopmental outcome in children with inherited metabolic disorders.
\end{abstract}

Copyright @ 2014, Indian Epilepsy Society. Published by Reed Elsevier India Pvt. Ltd. All rights reserved.

\section{Introduction}

Inherited metabolic disorders are a rare cause of epilepsy. ${ }^{1}$ However, in many metabolic disorders, seizures are the predominant symptom especially in newborns and infants e.g. pyridoxine dependent seizures, biotinidase deficiency and glucose transporter defect. It is most important to look for those inborn errors of metabolism which are treatable with supplementation of vitamins and cofactors or special diets. We report two unusual cases of inherited metabolic disorders with associated epilepsy.

\section{Case 1}

A 10-month-old male infant presented with developmental delay and jerky movements of the head and limbs since 6 months of age. He was the second child of nonconsanguineous parentage. The antenatal and perinatal periods were uneventful. He achieved social smile at 3 months and partial neck holding at 5 months. Since 6 months of age, parents noticed jerky movements with flexion of the head and upper limbs, suggestive of flexor spasms. These movements would occur in clusters whenever the child woke up from

\footnotetext{
* Corresponding author. Division of Pediatric Neurology, Department of Pediatrics, Lady Hardinge Medical College and Associated Kalawati Saran Children's Hospital, New Delhi 110001, India.

E-mail address: sharma.suvasini@gmail.com (S. Sharma). 
sleep. The parents did not seek any treatment for these movements. The parents also noticed progressive stiffness of both the limbs and intermitted twisting postures of the hands and feet since 8 months of age. His vision and hearing were normal. There were no other seizure types. At the time of presentation, he had partial neck holding, was recognizing his mother and cooing. He had not started holding objects yet. His elder brother had died at 4 years of age due to pneumonia. He had been developmentally normal.

Examination revealed an alert infant with no facial dysmorphism or neurocutaneous features. His head circumference was $48 \mathrm{~cm}$ (>2 SD). His weight and length were age appropriate. The general physical and systemic examination revealed no abnormalities. Neurological examination revealed increased tone, brisk muscle stretch reflexes and bilateral extensor plantar responses. He also had hands and feet dyskinesias. The fundus examination was normal.

Investigations revealed normal hemogram, liver and kidney function tests. The EEG showed modified hypsarrhythmia (Fig. 1). The MRI of the brain showed hyperintense signal changes involving bilateral basal ganglia with fronto-temporal atrophy (Fig. 2). The tandem mass spectrometry of blood showed elevated glutarylcarnitine \& low carnitine levels. His Urine gas chromatography and mass spectrometry showed highly elevated glutaric acid levels ( $>10,000 \mathrm{mmol} /$ mol of creatinine).

A diagnosis of glutaric aciduria type 1 with West syndrome was made. The patient was started on riboflavin, carnitine and oral prednisolone $(2 \mathrm{mg} / \mathrm{kg} /$ day $)$. His spasms subsided within 5 days of starting steroids, which were tapered off after 2 weeks. The repeat EEG showed resolution of hypsarrhythmia. The patient was initiated with physical rehabilitation. Six months after the diagnosis, he has shown some improvement - he has achieved neck holding and has started reaching out for objects.

\section{Case 2}

An 18-month-old boy presented with history of jerky movements of the head along with regression of developmental milestones for the last 25 days. The patient was apparently well 25 days back when he developed fever and cough, which lasted for three days. On the third day of illness, the parents noticed jerky movements of the head with head flexion. These movements occurred multiple times in a day. There was no history of up-rolling of eyeballs or limb movements. The patient gradually lost the ability to walk, sit and talk over the next two weeks. He also stopped recognizing his parents. He also became drowsy and lethargic.

He had a similar episode at 13 months of age. During that episode, he had developed fever, cough and fast breathing. Then he developed jerky head movements and regression of milestones. He had been admitted in a private nursing home, where he was diagnosed to have pneumonia. He recovered completely and had regained his milestones within 7 days. He was the first child of non-consanguineous parentage. The antenatal and perinatal periods were uneventful. His developmental milestones were age appropriate prior to this illness. The family history was not significant.

On examination the child was lethargic but responsive. The anthropometry and vital parameters were normal. There was no facial dysmorphism. The general physical and systemic examination was normal. Neurological examination showed infrequent head myoclonic jerks, mild central hypotonia, normal muscle stretch reflexes and bilateral extensor plantar responses. There were no meningeal signs.

The MRI of the brain was normal. The EEG showed chaotic background with high voltage activity with intermixed spikes arising from bilateral leads (Fig. 3). There were also

Bipolar Montage, Sensitivity $7 \mu \mathrm{v} / \mathrm{mm}$, Low cut $1 \mathrm{~Hz}$, High cut $70 \mathrm{~Hz}$, Timebase $30 \mathrm{~mm} / \mathrm{s}$

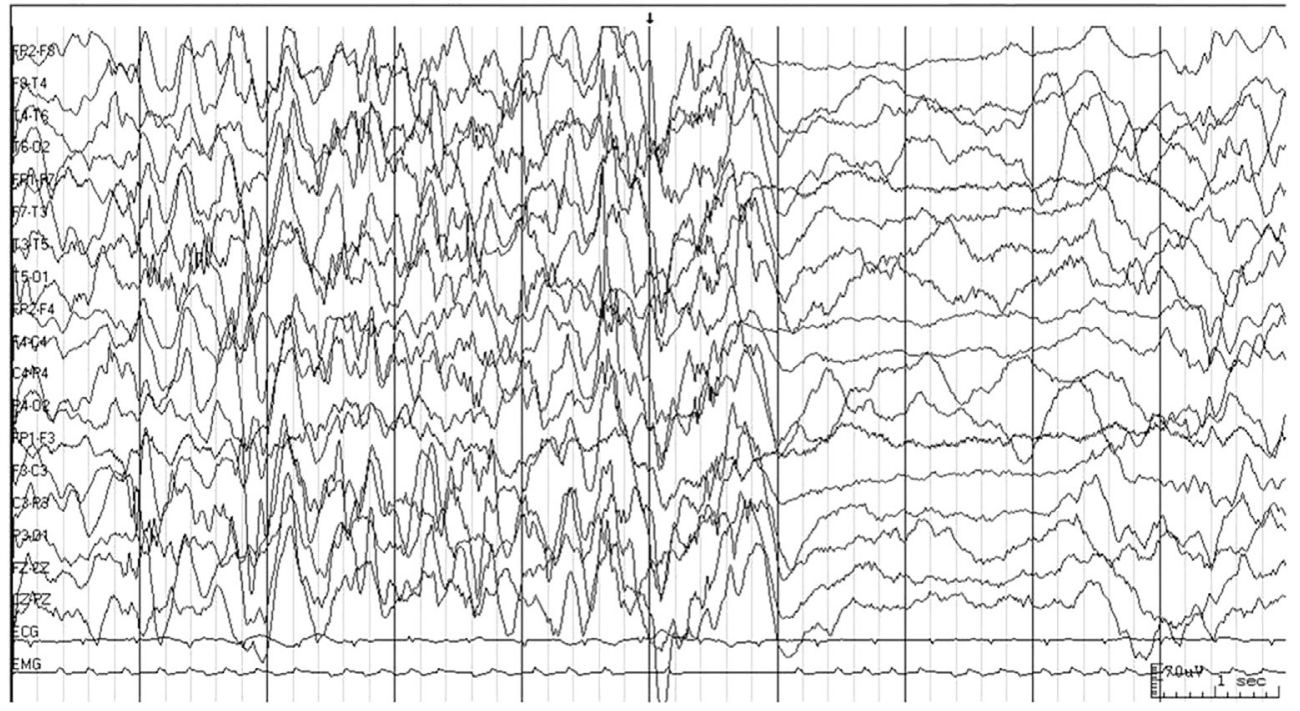

Fig. 1 - EEG of case 1: The sleep EEG shows a chaotic background with bilateral asynchronous high voltage delta activity with intermixed spikes and sharp waves followed by a period of electrodecrement. The pattern was suggestive of modified hypsarrhythmia. 


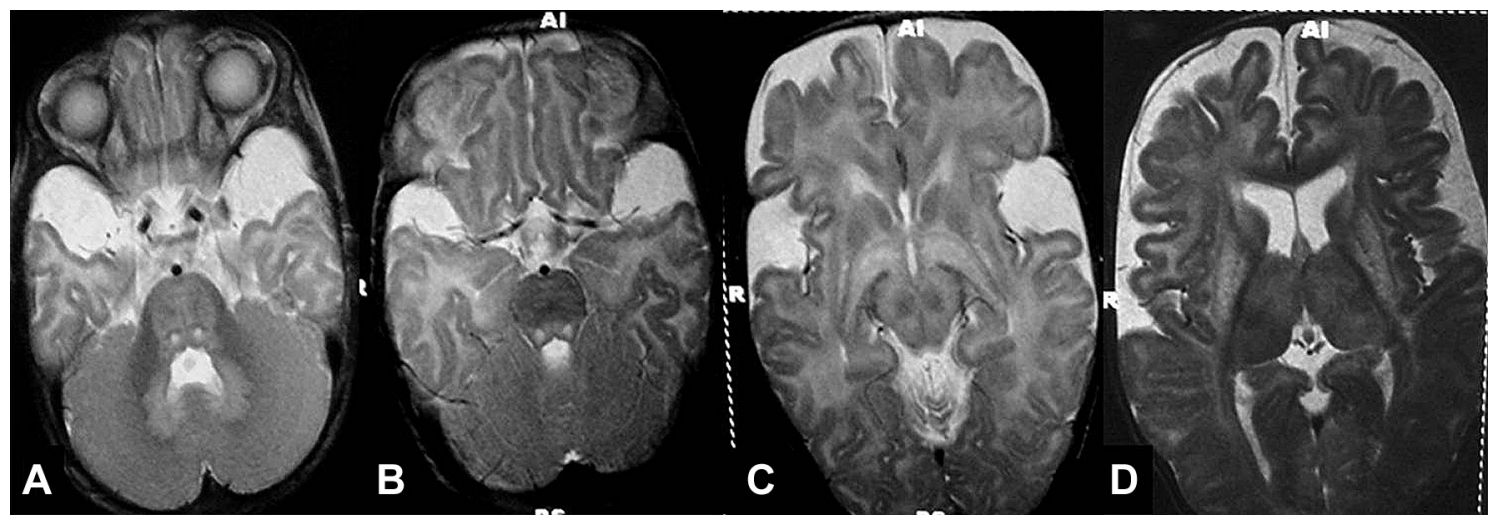

Fig. 2 - MRI of the brain of case 1: The axial T2W images show hyperintense signal changes involving the brainstem especially the dorsal tracts, the medial cerebellar hemispheres, bilateral basal ganglia (caudate and lentiform), thalami and cerebral white matter with fronto-temporal atrophy seen as prominent CSF spaces overlying the convexity and wide open sylvian fissures with CSF collections anterior to the temporal poles.

generalized polyspike wave discharges with electrodecrement. The blood ammonia, lactate, arterial blood gas analysis were normal and there was no urinary ketosis. The blood tandem mass spectrometry showed increased levels of leucine, isoleucine and valine. The urine gas chromatography mass spectrometry showed urine ketosis, and elevation of 3hydroxy-butyrate and dicarboxylic aciduria. The findings were suggestive of maple syrup urine disease.

Parents were advised a low protein diet. The child also received thiamine, sodium valproate and oral prednisolone. His myoclonic jerks subsided within 3 days. He became more alert and started recognizing his parents by the time of discharge. At 3 months follow up, he has started sitting and vocalizing bisyllables. A repeat EEG obtained 3 months later was normal.

\begin{abstract}
4.
We report describes two cases with neurometabolic disorder presenting with seizures. The inborn errors of metabolism are infrequent cause of epilepsy but their early recognition and appropriate management is pivotal.

Table 1 describes the metabolic disorders causing epilepsy. The underlying mechanisms may vary according to the metabolic disorder and includes deficiency of a vitamin or a cofactor, cerebral energy deficiency, chemical or physical disruption of neurotransmission, direct toxicity of the accumulating storage material or intermediates, associated hyperammonemia or hypoglycemia or electrolyte disturbances. $^{1}$
\end{abstract}

Bipolar Montage, Sensitivity $15 \mu \mathrm{v} / \mathrm{mm}$, Low cut 1 Hz, High cut $70 \mathrm{~Hz}$, Timebase $30 \mathrm{~mm} / \mathrm{s}$

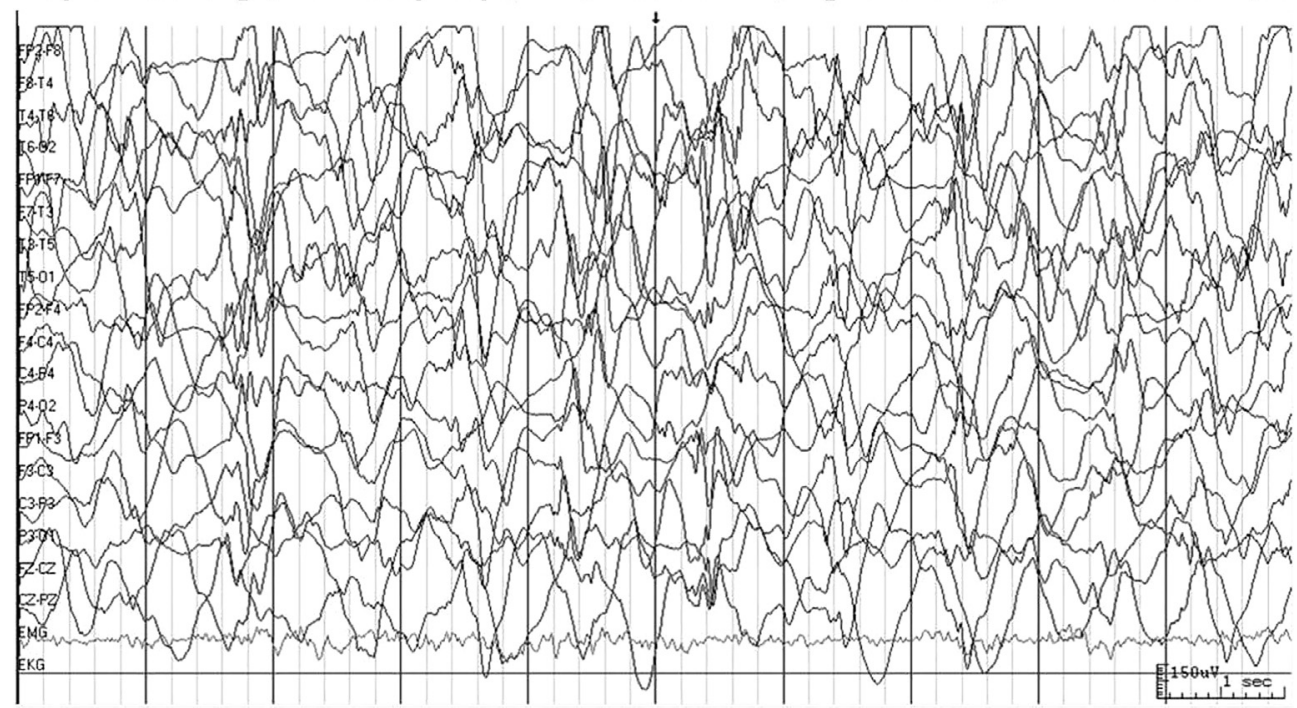

Fig. 3 - EEG of case 3 shows chaotic high voltage activity with intermixed spikes and sharp waves arising independently from bilateral leads. 
Table 1 - Metabolic disorders causing epilepsy.

\begin{tabular}{|c|c|}
\hline Treatable causes & Others \\
\hline Multiple carboxylase deficiency & Molybdenum cofactor and \\
\hline Pyridoxine dependent epilepsy & sulfite oxidase deficiencies \\
\hline \multirow{2}{*}{$\begin{array}{l}\text { Pyridox }(\mathrm{am}) \text { ine } 5^{\prime} \text {-phosphate } \\
\text { oxidase deficiency }\end{array}$} & Menkes disease \\
\hline & Peroxisomal disorders \\
\hline \multirow{3}{*}{$\begin{array}{l}\text { GLUT1 deficiency syndrome } \\
\text { Disorders of creatine } \\
\text { metabolism }\end{array}$} & Congenital disorders of \\
\hline & glycosylation \\
\hline & Mitochondrial disorders \\
\hline \multirow{2}{*}{$\begin{array}{c}\text { Disorders of coenzyme } \\
\mathrm{Q}_{10} \text { biosynthesis }\end{array}$} & Organic acidemias \\
\hline & Aminoacidopathies \\
\hline \multirow[t]{6}{*}{ Disorders of serinebiosynthesis } & Urea cycle disorders \\
\hline & Non-ketotic hyperglycinemia \\
\hline & Purine metabolism defects \\
\hline & GABA transaminase deficiency \\
\hline & Storage disorders \\
\hline & Progressive myoclonic epilepsies \\
\hline
\end{tabular}

Glutaric aciduria (GA) type 1 is caused by deficiency of glutaryl CoA dehydrogenase deficiency resulting in accumulation of glutarate, 3-hydroxyglutarate and glutaconate. Seizures are rarely seen in GA type 1 and usually occur during episodes of acute encephalopathy. ${ }^{2,3}$ Rather majority of the paroxysmal movements, which may be misdiagnosed as seizures, appear to be dystonic episodes. ${ }^{4}$ The accumulating glutarate has recognized excitotoxic effects via N-methyl-Daspartate (NMDA) receptor ${ }^{5}$ and may thus be epileptogenic.

West syndrome has never been reported with GA type 1 previously although it has been rarely reported with other organic acidemias like propionic academia, ${ }^{6,7}$ methylmalonic academia, ${ }^{8}$ and D-glyceric aciduria. ${ }^{9}$ Thus, the case 1 further expands the phenotypic spectrum of GA type 1.

Maple syrup urine disease (MSUD) is caused by mitochondrial branched chain $\alpha$-ketoacid dehydrogenase complex deficiency resulting in accumulation of branched chain amino acids and $\alpha$-ketoacids. Five forms of MSUD have been described: classic, intermediate, intermittent, thiamine responsive and dihydrolipoyl dehydrogenase deficiency.

Case 2 had intermittent MSUD presenting with episodic encephalopathy, seizures and neuroregression with recovery. The patients with intermittent MSUD can have intractable seizures during an acute episode and the acute episodic deterioration can be fatal. However, with early diagnosis and treatment, the patients can have normal or near normal neurodevelopment. Seizures have also been described in other forms of MSUD ${ }^{10}$ The neurotoxicity is predominantly mediated by leucine and its transamination product 2-ketoisocaproate. ${ }^{11}$

Thus, inborn errors of metabolism should always be excluded in a child with unexplained seizures, especially if they are refractory to treatment. Table 2 shows the clinical cues that may help the neurologist to suspect an inborn error of metabolism in a child with epilepsy. This report describes the first case of GA type 1 presenting with West syndrome and a child with intermittent MSUD presenting with metabolic and epileptic encephalopathy.

\section{Conflicts of interest}

All authors have none to declare.
Table 2 - Pointers towards an inborn error of metabolism in children with epilepsy. ${ }^{12}$

Associated global developmental delay

Associated movement disorder - creatine deficiency, organic acidemia

Worsening of seizures before meals - GLUT1 deficiency

Vomiting - urea cycle disorders

Abnormal urine odor - maple syrup urine disease, phenylketonuria

Accelerated growth (macrosomia, tall stature) - GABA transaminase deficiency

Facial dysmorphism - Zellweger syndrome

Hair and skin abnormalities - Menkes disease, biotinidase deficiency

Albinism - phenylketonuria

Dislocated lens - sulphite oxidase deficiency

Inverted nipples, abnormal fat pads - congenital disorders of glycosylation

Organomegaly, coarse facies - storage disorders

Multi-system involvement - mitochondrial disorders, congenital disorders of glycosylation, peroxisomal disorders

\section{R E F E R E N C ES}

1. Rahman S, Footitt EJ, Varadkar S, Clayton PT. Inborn errors of metabolism causing epilepsy. Deu Med Child Neurol. 2013;55:23-36.

2. Kyllerman M, Skjeldal OH, Lundberg M, et al. Dystonia and dyskinesia in glutaric aciduria type I: clinical heterogeneity and therapeutic considerations. Mou Disord. 1994;9:22-30.

3. McClelland VM, Bakalinova DB, Hendriksz C, Singh RP. Glutaric aciduria type 1 presenting with epilepsy. Dev Med Child Neurol. 2009;51:235-239.

4. Cerisola A, Campistol J, Pérez-Dueñas B, et al. Seizures versus dystonia in encephalopathic crisis of glutaric aciduria type I. Pediatr Neurol. 2009;40:426-431.

5. De Mello CF, Kölker S, Ahlemeyer B, et al. Intrastriatal administration of 3-hydroxyglutaric acid induces convulsions and striatal lesions in rats. Brain Res. 2001;916:70-75.

6. Aldamiz-Echevarría Azuar L, Prats Viñas JM, Sanjurjo Crespo P, Prieto Perera JA, Labayru Echeverría MT. Infantile spasms as the first manifestation of propionic acidemia. An Pediatría Barc Spain. 2005;63:548-550.

7. Harris DJ, Thompson RM, Wolf B, Yang BI. Propionyl coenzyme A carboxylase deficiency presenting as non-ketotic hyperglycinaemia. J Med Genet. 1981;18:156-157.

8. Guevara-Campos J, González-de-Guevara L, Medina-Atopo M. Methylmalonic aciduria associated with myoclonic convulsions, psychomotor retardation and hypsarrhythmia. Rev Neurol. 2003;36:735-737.

9. Topcu M, Saatci I, Haliloglu G, Kesimer M, Coskun T. Dglyceric aciduria in a six-month-old boy presenting with West syndrome and autistic behaviour. Neuropediatrics. 2002;33:47-50.

10. Lee W-T. Disorders of amino acid metabolism associated with epilepsy. Brain Dev. 2011;33:745-752.

11. Zinnanti WJ, Lazovic J, Griffin K, et al. Dual mechanism of brain injury and novel treatment strategy in maple syrup urine disease. Brain J Neurol. 2009;132:903-918.

12. Aneja S, Jain P. Refractory epilepsy in children. Indian J Pediatr. 2014 (in press). 